\section{Cost of Wind Energy: Comparing Distant Wind Resources to Local Resources in the Midwestern United States}

\author{
DAVID C. HOPPOCK${ }^{\dagger}$ A N D \\ D A L A PATIÑ O-ECHEVERRI*, \\ Climate Change Policy Partnership - Nicholas Institute \\ For Environmental Policy Solutions, \\ Duke University, Durham, North Carolina, \\ and Nicholas School of the Environment, \\ Duke University, Durham, North Carolina
}

Received March 8, 2010. Revised manuscript received September 12, 2010. Accepted September 14, 2010.

The best wind sites in the United States are often located far from electricity demand centers and lack transmission access. Local sites that have lower quality wind resources but do not require as much power transmission capacity are an alternative to distant wind resources. In this paper, we explore the tradeoffs between developing new wind generation at local sites and installing wind farms at remote sites. We first examine the general relationship between the high capital costs required for local wind development and the relatively lower capital costs required to install a wind farm capable of generating the same electrical output at a remote site, with the results representing the maximum amount an investor should be willing to pay for transmission access. We suggest that this analysis can be used as a first step in comparing potential wind resources to meet a state renewable portfolio standard (RPS). To illustrate, we compare the cost of local wind ( $\sim 50 \mathrm{~km}$ from the load) to the cost of distant wind requiring new transmission ( $\sim 550-750$ $\mathrm{km}$ from the load) to meet the Illinois RPS. We find that local, lower capacity factor wind sites are the lowest cost option for meeting the Illinois RPS if new long distance transmission is required to access distant, higher capacity factor wind resources. If higher capacity wind sites can be connected to the existing grid at minimal cost, in many cases they will have lower costs.

\section{Introduction}

Wind is the fastest growing (1), and perhaps the lowest cost renewable generation resource in the United States (2). Highquality wind generation sites are available across a large area of the United States and could be the best resource to help meet renewable portfolio standards (3) (RPS) in a majority of states. As of June 2010, twenty-nine states have passed an RPS, twenty-seven of which require that a percentage of electricity consumption come from renewable sources (4) (3). Despite the low relative cost of wind, its widespread availability, and mandates for increasing renewable energy, wind generation faces significant barriers to future growth.

\footnotetext{
* Corresponding author e-mail: dalia.patino@duke.edu.

${ }^{\dagger}$ Climate Change Policy Partnership - Nicholas Institute For Environmental Policy Solutions.

${ }^{\ddagger}$ Nicholas School of the Environment and Earth Sciences.
}

The best wind sites are located far from demand centers and lack transmission access, and the permitting, siting, and cost allocation of new transmission to access these resources is considered the greatest barrier to increasing wind generation (1). An alternative to the development of high quality wind sites is the development of lower quality wind resources close to load centers. This paper analyzes both alternatives while performing a case study of the state of Illinois, which lies in a region with diverse wind resources and has an RPS law mandating increased wind generation (5).

Numerous studies have analyzed how to best utilize the wind resources in the United States. DeCarolis and Keith (6) and Greenblatt et al. (7) have analyzed the cost effectiveness of using high quality wind resources far from major loads, combined with energy storage, to reduce carbon dioxide $\left(\mathrm{CO}_{2}\right)$ emissions. Cavallo (8) estimated the cost of large-scale wind combined with energy storage relative to other generation options, while Pattanariyankool and Lave (9) and Denholm and Sioshansi (10) have studied the optimization of storage and transmission to reduce transmission costs for wind. Lewis (11) optimized the location of new wind generation to match high locational marginal prices for electricity, and Greenblatt et al. note the trade-off between transmission distance and wind quality. But to our knowledge, there are no other studies comparing high quality, distant wind with local, lower quality wind.

\section{Method}

In this paper, we examine the capital costs of building new wind generation and transmission from the wind site to a demand center and compare those costs for different wind quality categories grouped by capacity factor. This allows us to explore the trade-off between wind sites with high capacity factors far from the load, versus sites with lower capacity factors closer to the load. We estimate the economic benefit of a higher quality site in terms of the reduced capital cost required to achieve the same power output and argue that this economic benefit is the maximum that a rational investor should be willing to pay for power transmission capacity to harvest the higher quality wind.

Successfully integrating large quantities of wind generation $(>5-10 \%)$ into balancing areas presents challenges for load balancing, generator dispatch, contingency planning, and transmission stability (12), and a study that estimates the real cost of integrating significant quantities of wind power requires extensive power flow and generation dispatch modeling that is beyond the scope of this paper. We focus on the effect that generation capacity factor, distance to load, and transmission losses have on the capital cost of meeting an RPS with new wind generation. This simplification requires the assumption that power generation capacity factor fully characterizes a wind site. Implicit is the assumption that differences in turbines and wind speed do not affect the operations and maintenance costs of turbines and that revenues from the sale of high and low quality wind generation are equal for the same quantity of generation, which makes the total capital cost of new wind generation and transmission the decision criteria to select the wind resources that will be developed. The data we use for this analysis uses different classes of wind turbines based on estimated wind speeds and assumes that lower quality wind sites require higher turbine hub heights, creating different capital costs per unit of generation for different wind speeds (13). Thus, if the capital cost at sites with high capacity factors is WUC, then the capital cost at sites with low capacity factors 
is LQCM*WUC, where LQCM is the Low Quality Wind Cost Multiplier that accounts for higher turbine hub heights.

A general expression of the total savings from reducing the capital costs of developing a wind site with capacity factor $\mathrm{CF}+\Delta \mathrm{CF}$, relative to the capital costs of developing the local site with capacity factor CF, is given by eq 1 (see Supporting Information section 1.1 for derivation)

$$
\begin{aligned}
& \text { Capital Cost Savings }=\mathrm{Z} \frac{\text { WUC }}{8,760} \\
& \left.\qquad \frac{\frac{L Q C M}{C F_{l w}\left(1-T C_{l w}\right)\left(1-T L_{l w}\right)}-}{\left(C F_{l w}+\Delta C F\right)\left(1-T C_{d w}\right)\left(1-T L_{d w}\right)}\right)
\end{aligned}
$$

where $Z$ is the annual generation requirement ( $\mathrm{kWh} /$ year), 8670 is the number of hours in a year, WUC is the installed wind capital cost estimate ( $\$ / \mathrm{kW}), L Q C M$ is the cost multiplier for low quality wind requiring higher hub height (see Section 3.4), $C F$ is the unconstrained capacity factor, $\triangle C F$ is the increase in unconstrained $\mathrm{CF}$ at distant wind site relative to local site, $T L$ is the transmission loss, as a percentage of total wind energy injected into the grid, TC is the transmission constraint, as a percentage of the total wind energy injected into the grid that cannot be delivered because of inadequate transmission capacity, $l w$ is the local wind, and $d w$ is the distant wind.

As mentioned above, eq 1 is also an expression for the maximum amount an investor with an annual generation requirement of $\mathrm{Z}$ (kWh/year) and access to a wind site with a capacity factor CF should be willing to pay for transmission capacity from a wind site with capacity factor $\mathrm{CF}+\Delta \mathrm{CF}$ for the life of the investment. The willingness to pay for transmission depends on the capacity of the transmission and expected transmission losses. In the cases where new power transmission lines are required, the equation implies that investors will need to solve an optimization problem where the benefits and costs of different voltage transmission lines and their corresponding transmission capacity and losses are taken into account. Such an optimization problem consists of selecting the characteristics of the transmission line (AC or DC, and voltage level) and wind farm installed capacity that minimize the cost of electricity $(\mathrm{COE})(\$ / \mathrm{kWh})$, while meeting a specific annual power requirement $\mathrm{Z}$.

An investment decision can then be informed by comparing the COE of local and distant sites under different scenarios. Equation 2 presents the $\mathrm{COE}$ of wind site $k$, assuming an economic life $T$ and discount rate $r$

$$
\operatorname{COE}_{k}(Z)=\frac{\operatorname{Cap}_{k}(Z) \times W U C+T C C^{*}}{\sum_{t=1}^{T} Z(1+r)^{-t}}
$$

TCC ${ }^{*}$ represents the total transmission capital costs (\$) of the optimal transmission line to connect site $k$ to the grid. The optimal transmission line (AC or DC, voltage) is selected using the optimization program described in Supporting Information section 1.2, accounting for transmission losses, transmission capacity, and specific information about wind site $k$ including 1 ) the distance the power must be transmitted, 2) the installed capacity at the wind site, and 3) time series wind generation data.

\section{Example: Determining the Lowest Cost Wind Resource To Meet the Illinois RPS}

In order to illustrate the trade-off between local and distant potential wind sites to meet a state RPS, we use eq 1 to find the maximum amount that investors should pay to access distant, high CF wind sites, relative to local, low CF resources to meet the Illinois RPS. The Illinois RPS requires that $5 \%$ of electricity consumed in the state come from renewable resources, increasing to $25 \%$ in 2025 , of which at least $60 \%$ must come from wind (see Supporting Information section 2). Equation 1 requires site-specific information about $\mathrm{CF}$ and turbine cost (WUC and LQCM), so for this illustration we use a major substation outside of Chicago as the demand source. We then utilize data identified by the Eastern Wind Integration and Transmission Study (EWITS) for wind sites in Illinois, Wisconsin, Minnesota, Iowa, South Dakota, and North Dakota. The EWITS data set includes wind turbine height data and output data from which we can calculate CF and LQCM values.

3.1. Identifying and Characterizing Potential Wind Sites. EWITS, commissioned by the National Renewable Energy Laboratory (NREL), uses a mesoscale model (see Supporting Information section 3) with historical wind data to identify 580 GWs of potential on-shore wind sites in the Eastern Interconnect (14). For each site, the study provides the following: location (latitude and longitude); ground elevation; time series estimates of wind speed at 80 and $100 \mathrm{~m}$ above ground level from 2004 to 2006; site generation capacity; ten-minute generation estimates for International Electro-technical Commission (IEC) class 1,2, and 3 turbines, including losses (class 1 and 2 at $80 \mathrm{~m}$, class 3 at $100 \mathrm{~m}$ ); and the optimal IEC class turbine for each year (15).

To characterize each site, we used the generation data for the optimal IEC turbine to estimate the 3 -year average $\mathrm{CF}$ at each site. These data were calculated by dividing the total generation for the three years (watt-hours) by the site generation capacity (watt), multiplied by the number of hours in the three years. For those sites for which the optimal turbine changed between years, we assumed the installation of the highest IEC class turbine.

3.2. Capacity Factors of Wind Resources to Meet the Illinois RPS. For the study area, the estimated CF of potential wind sites tends to increase further from the load. This is illustrated by Figure 1, which shows the location of selected potential wind sites grouped by capacity factor (see Supporting Information section 4 for more information). Based on NREL's data on potential wind sites and our CF estimates, we identified four wind categories that represent wind resources available to meet the Illinois RPS: 1) local wind with a $36 \%$ CF $50 \mathrm{~km}$ from the load, accessed with $100-\mathrm{m}$ hub height IEC Class 3 turbines; 2) $39.5 \%$ CF wind $550 \mathrm{~km}$ from the load, accessed with 80-m IEC Class 2 turbines; 3 ) $41 \%$ CF wind $650 \mathrm{~km}$ from the load, accessed with 80 -m IEC Class 2 turbines; and 4) 42\% CF wind $750 \mathrm{~km}$ from the load, accessed with $80-\mathrm{m}$ IEC Class 2 turbines. These wind categories, referred to as wind Distance Capacity Factor (DCF) categories, represent groups of potential wind sites with higher capacity factors than other sites closer to the load. The CF of the best potential wind sites in the NREL data set are higher than the U.S. average; we discuss the causes of this discrepancy in Supporting Information section 5.

3.3. Capital Costs of Wind Generation. Installed capital costs for wind generation vary by project due to differences in turbine costs, development, and installation costs (labor, geography, regulatory, and land costs) (1). The Department of Energy's (DOE) 2008 Wind Technologies Market Report, based on a Lawrence Berkeley National Laboratory (LBNL) database of U.S. wind projects (1), estimates that the capacityweighted average installed cost of wind generation projects completed in 2008 was $\$ 1915 / \mathrm{kW}$. The report further projected that installed capital costs would average $\$ 2120$ / $\mathrm{kW}$ in 2009. Projects completed during 2007 and 2008 in the Great Lakes (MI, WI, IL, OH) and Heartland region (AR, MO, IA, MN, ND, SD, NE, KS, OK) had an estimated capacityweighted average installed cost of $\$ 1913 / \mathrm{kW}$, approximately $10.8 \%$ lower than the 2009 projection. The DOE report 


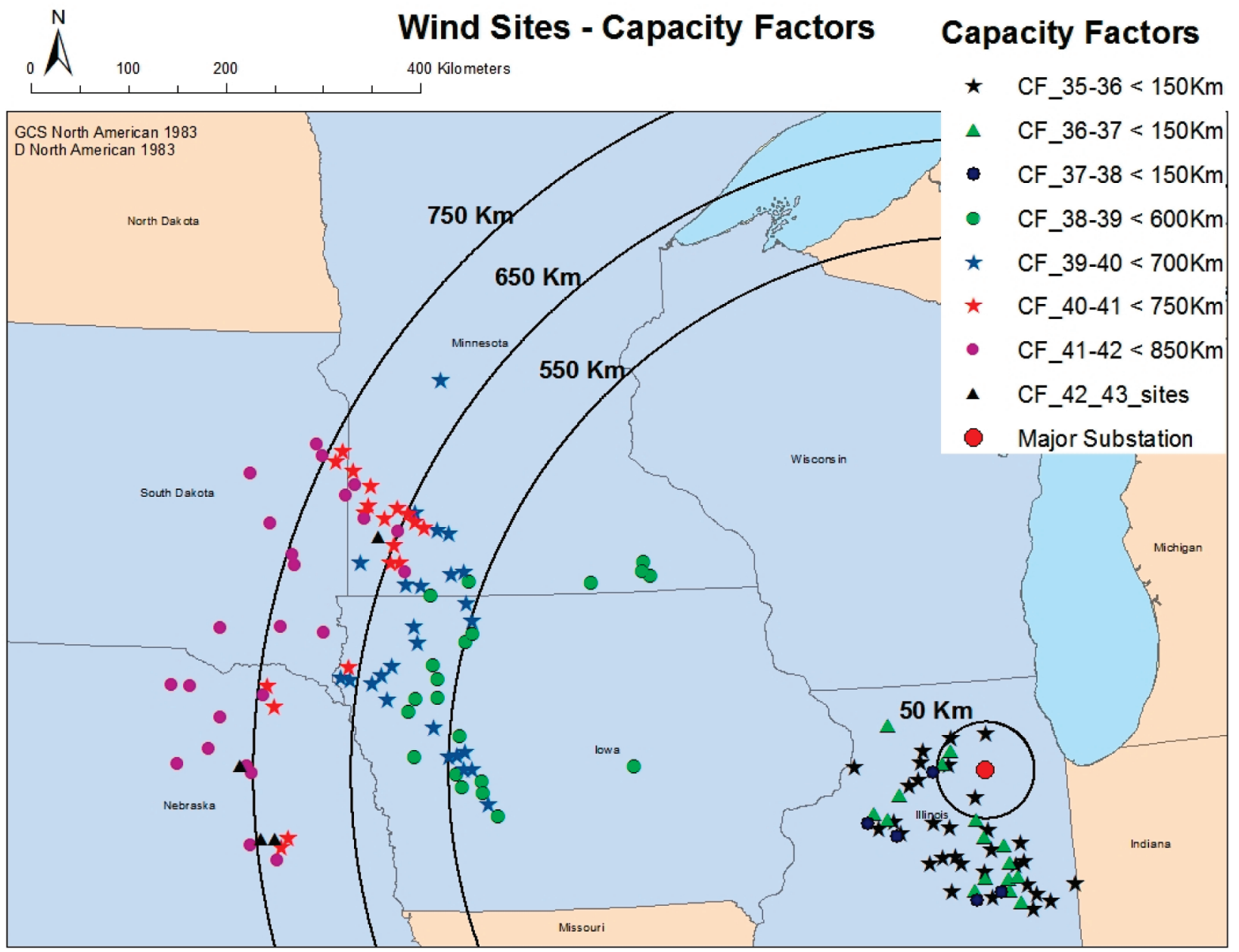

FIGURE 1. Location of potential wind sites grouped by CF. For each CF range, only sites with distances to the load less than the distances in the legend are included. Sites with CFs less than $35 \%$ are not included.

attributes the price increase to higher raw material prices and manufacturing constraints. In order to account for the range in wind turbine capital cost estimates we use DOE's 2009 forecast as a high estimate, and the 2007-2008 average in the Heartland region $(\$ 1913 / \mathrm{kW})$ as a low estimate. Thus, the capital cost estimates for distant wind (WUC in eq 1) are $\$ 2120 / \mathrm{kW}$ and $\$ 1913 / \mathrm{kW}$.

3.4. Cost Differences Due to Hub Height and IEC Class. IEC class turbines are designed to cope with wind regimes that have varying average speeds, turbulence, and extreme gusts. Class 1, 2, and 3 turbines are designed for high, medium, and low speed winds, respectively (16). The main differences between these turbines are blade length, gear ratios, and mechanical robustness (16). In addition to differences between IEC classes, wind turbines have different hub heights, with higher hub heights used to access better wind resources. The NREL data set assumes that IEC class 3 turbines used at lower wind speed sites have a 100-m hub height, whereas class 1 and 2 turbines have an $80-\mathrm{m}$ hub height. For this study, high capacity factor DCF categories are assumed to utilize class 2 turbines with 80 -m hub heights, and the local wind resource is assumed to utilize IEC class 3 turbines with 100-m hub heights.

To compare the cost of a 100-m IEC class 3 turbine to the cost of an 80-m class 2 turbine, we utilized NREL's Wind Design Cost and Scaling Model (2006) (17) and found that the installed generation costs of 100-m IEC class 3 turbines are $14 \%$ higher than those of 80 -m IEC class 2 turbines (see Supporting Information section 6). Therefore, LQCM in eq $1=1.14$, which makes our low and high capital cost estimates for local wind $\$ 2181 / \mathrm{kW}$ and $\$ 2417 / \mathrm{kW}$, respectively.
3.5. Capital Cost Savings from Increases in Capacity Factor. Figure 2 presents the capital cost savings calculated using eq 1 . These savings represent the maximum amount an investor should be willing to pay for unconstrained transmission access $(\mathrm{TC}=0)$, ignoring transmission losses $(\mathrm{TL}=0)$ to the higher CF DCF wind resources. If transmission congestion or insufficient installed power transmission capacity reduces the $\mathrm{CF}$ of those sites, the maximum amount an investor should pay for transmission access should be reduced accordingly.

Figure 2 shows that generating 1000 GWh per year, or $0.7 \%$ of Illinois demand $\left(145 \times 10^{3} \mathrm{GWh}\right)$ in 2005 (18), by developing the highest quality wind DCF category ( $42 \% \mathrm{CF}$ ) at a cost of $\$ 2120 / \mathrm{kW}$ reduces installed capital costs by $25 \%$, or $\$ 190$ million, relative to the local wind (36\% CF). Based on these capital cost savings, investors must determine if they can obtain transmission access to higher CF wind at a lower cost while accounting for transmission losses and constraints.

3.6. Transmission Constraints. The values in Figure 2 represent the capital costs savings for wind projects if there are no transmission constraints reducing CF. In reality, the transmission that connects the wind farm to the power grid might have a power transmission capacity lower than the installed capacity of the wind farm, which will effectively reduce the $\mathrm{CF}$ of the wind farm (e.g., in eq 1, TC $>0$ ). This occurs because it is sometimes more economical to build transmission with lower capacity than the nameplate capacity of an intermittent generation source such as wind (9).

To account for potential reductions in CF due to transmission constraints that may occur if the installed capacity 


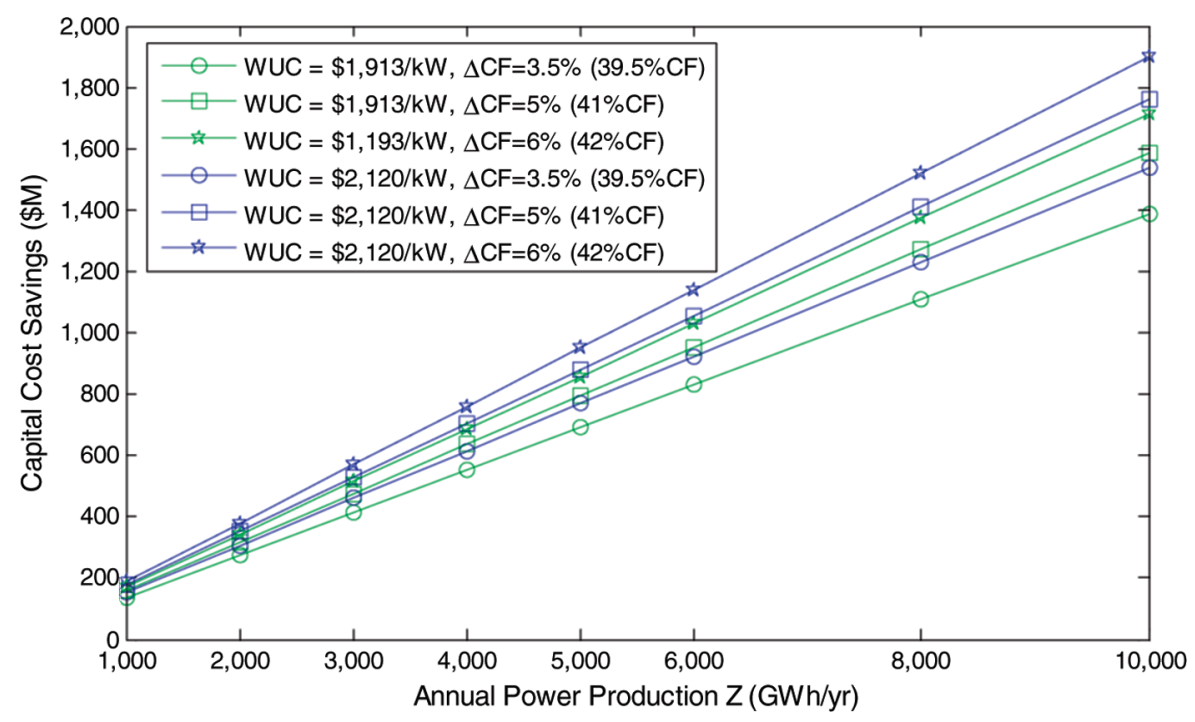

FIGURE 2. Capital cost savings due to increases in CF in \$M. Calculated with eq 1, using the high and low estimates of wind generation capital costs (WUC) and CF $=36 \%, \mathrm{TC}=0 \%, \mathrm{TL}=0 \%$, and $\mathrm{LOCM}=1.14$.

\section{TABLE 1. Transmission Constrained Capacity Factors ${ }^{a}$}

\section{generation capacity}

\begin{tabular}{|c|c|c|c|c|c|c|c|c|c|c|c|c|c|c|c|c|}
\hline \multicolumn{3}{|c|}{200 MW } & \multicolumn{3}{|c|}{$400 \mathrm{MW}$} & \multicolumn{3}{|c|}{$800 \mathrm{MW}$} & \multicolumn{2}{|c|}{2000 MW } & \multicolumn{3}{|c|}{$4000 \mathrm{MW}$} & \multicolumn{3}{|c|}{$\begin{array}{c}\text { transmission } \\
\text { capacity (MW) }\end{array}$} \\
\hline 115 & 345 & 765 & 115 & 345 & 765 & 115 & 345 & 765 & 115345 & 765 & 115 & 345 & 765 & 115 & 345765 & HVDC \\
\hline $24 \%$ & $36 \%$ & $36 \%$ & $15 \%$ & $36 \%$ & $36 \%$ & $8 \%$ & $36 \%$ & $36 \%$ & $3 \% \quad 27 \%$ & $36 \%$ & $2 \%$ & $17 \%$ & $36 \%$ & 78 & 9405104 & NA \\
\hline $10 \%$ & $40 \%$ & $40 \%$ & $5 \%$ & $37 \%$ & $40 \%$ & $3 \%$ & $24 \%$ & $40 \%$ & $12 \%$ & $38 \%$ & $1 \%$ & $6 \%$ & $26 \%$ & 24 & 2831534 & 2975 \\
\hline $8 \%$ & $41 \%$ & $41 \%$ & $4 \%$ & $34 \%$ & $41 \%$ & $2 \%$ & $21 \%$ & $41 \%$ & $10 \%$ & $36 \%$ & $<1 \%$ & $5 \%$ & $23 \%$ & 24 & 2401300 & 2970 \\
\hline $7 \%$ & $42 \%$ & $42 \%$ & $4 \%$ & $32 \%$ & $42 \%$ & $2 \%$ & $19 \%$ & $42 \%$ & $1 \% 9 \%$ & $34 \%$ & $<1 \%$ & $5 \%$ & $21 \%$ & 17 & 2081128 & 2966 \\
\hline
\end{tabular}

transmission voltage $(\mathrm{kV})$ local $36 \%$ CF wind, $50 \mathrm{~km}$ $39.5 \%$ CF wind, $550 \mathrm{~km}$ from $41 \%$ CF wind, $650 \mathrm{~km}$ from load $42 \%$ CF wind, $750 \mathrm{~km}$ from load

${ }^{a}$ HVAC transmission power transfer limits were estimated using HVAC transmission power transfer limit (MW) from St. Clair curves (see Supporting Information section 8). Compensated lines have reactive power compensation. HVDC is 500 $\mathrm{kV}$, bipolar line. $50 \mathrm{~km}$ transmission uncompensated, all other distances compensated.

of the wind farm exceeds the power transmission capacity of the line, we calculated the effective CF for each of the 1326 NREL potential wind sites. We looked specifically at transmission capacities between $50 \%$ and $95 \%$ of nameplate generation capacity, using 10-min time series generation data for three years. For the NREL potential wind sites, CF decreases an average of $22 \%$ when transmission capacity is $50 \%$ of the wind nameplate capacity and decreases an average of $2 \%$ when transmission capacity is $80 \%$ of nameplate capacity. This analysis also illustrates that the percent decrease in capacity factor is greater for sites with higher capacity factors (see Supporting Information section 7).

From Table 1, the impact of distance on the transmission capacity of high voltage alternating current (HVAC) lines is clear (see Supporting Information section 8). Transmission capacity at $550 \mathrm{~km}$ is less than one-third of the transmission capacity at $50 \mathrm{~km}$, and the transmission capacity at $750 \mathrm{~km}$ is approximately $26 \%$ less than the capacity at $550 \mathrm{~km}$.

3.7. Transmission Losses. Another cost of accessing wind sites far from the load is transmission losses. Resistive transmission losses increase linearly with distance for HVAC and HVDC lines. For this analysis we calculated resistance losses based on the time series output of the potential wind resource and the straight line distance from the wind site to the load for each HVAC and HVDC transmission option (see Supporting Information section 9). We ignore any nonresistive losses in HVAC lines as well as transformer and substation losses for HVAC and HVDC lines because all wind resources incur transformer and substation losses. Losses from AC-DC and DC-AC converters in HVDC lines are assumed to be $1.5 \%$.

Table 2 shows the capital cost savings from accessing higher CF with and without transmission losses. For this table, transmission losses are estimated using two scenarios: 1) transmission with the minimum voltage to avoid transmission CF constraints and 2) transmission with the highest voltage lines to minimize transmission losses. The capital cost savings with the highest voltage transmission represents the maximum amount an investor should pay over the lifetime of a project to access higher CF wind resources.

As seen in Table 2, accounting for transmission losses reduces the benefit of distant wind. For example, if an investor wants to generate $2000 \mathrm{GWh}$ of wind a year and uses the minimum transmission voltage required to avoid transmission CF constraints, the investor can save $\$ 282$ million on wind capital costs by utilizing $39.5 \%$ CF wind, relative to local wind. This increases to $\$ 303$ million if the investor can access the wind with $765 \mathrm{kV}$ transmission to minimize losses, but $765 \mathrm{kV}$ transmission costs more to build than $500 \mathrm{kV}$ transmission, creating an optimization problem for the investor who must account for both the cost of transmission losses and the cost of transmission access as mentioned in section 2 and described in Supporting Information section 1.2 .

3.8. Transmission Requirements for Additional Wind Capacity. In the most optimistic case for distant wind development, the wind farm would only be a few miles from existing transmission with enough capacity to deliver all of the generation to the load. In the most pessimistic case for distant wind development, connecting the wind farm to the load would require building new transmission capacity from the wind site to the load. A recent study by the Midwest ISO on meeting state RPS standards in the region (most of Illinois is in the Midwest ISO) concluded that the existing grid does not have the capacity to meet each state's RPS with wind power, and estimates that $7000-12,000 \mathrm{~km}$ of new transmis- 


\begin{tabular}{|c|c|c|c|c|c|c|c|c|c|c|c|c|c|c|c|}
\hline \multirow[b]{3}{*}{$\begin{array}{c}Z \\
(G W h / y r)\end{array}$} & & & & \multicolumn{6}{|c|}{$\begin{array}{l}\text { minimum transmission voltage for zero } \\
\text { transmission constraint, } \Delta \mathrm{CF} \text { (CF) }\end{array}$} & \multicolumn{6}{|c|}{ maximum transmission voltage, $\Delta \mathrm{CF}$ (CF) } \\
\hline & \multicolumn{3}{|c|}{ no transmission losses, $\Delta \mathrm{CF}$ (CF) } & \multicolumn{2}{|c|}{$3.5 \%(39.5 \%)$} & \multicolumn{2}{|c|}{$5 \%(41 \%)$} & \multicolumn{2}{|c|}{$6 \%(42 \%)$} & \multicolumn{2}{|c|}{$3.5 \%(39.5 \%)$} & \multicolumn{2}{|c|}{$5 \%(41 \%)$} & \multicolumn{2}{|c|}{$6 \%(42 \%)$} \\
\hline & $\begin{array}{c}3.5 \% \\
(39.5 \%)\end{array}$ & $\begin{array}{c}5 \% \\
(41 \%)\end{array}$ & $\begin{array}{c}6 \% \\
(42 \%)\end{array}$ & mill \$ & trans & & & mill \$ & trans & mill \$ & trans & mill \$ & trans & mill \$ & trans \\
\hline 1000 & & & & & & & & & & $\$ 153$ & & & & $\$ 189$ & \\
\hline & & & & & & & & & & & & & & & \\
\hline & & & & & HV & $\$ 5$ & & $\$ 5$ & & $\$ 451$ & & & & & \\
\hline & & & & $\$ 575$ & $\mathrm{HVL}$ & $\$ 666$ & HV & $\$ 7$ & HV & $\$ 597$ & & $\$ 6$ & & $\$ 737$ & $765 \mathrm{kV}$ \\
\hline & & & & & $H V L$ & $\$ 831$ & & & & $\$ 740$ & & & & & HVDC \\
\hline & & & & & & & & & & & & & & & HVDC \\
\hline 80 & & & & & & & & & & & & & & & HVDC \\
\hline & $\$ 1537$ & $\$ 1761$ & $\$ 1902$ & $\$ 1429$ & HVDC & $\$ 1652$ & HVDC & $\$ 1790$ & HVDC & $\$ 1429$ & HVDC & $\$ 1652$ & HVDC & $\$ 1790$ & HVDC \\
\hline
\end{tabular}

${ }^{a}$ Transmission for local wind is assumed to be the same voltage as for distant wind for all HVAC lines. When distant wind uses HVDC transmission the transmission for local wind is assumed to be $765 \mathrm{kV}$. WUC $=\$ 2120$.

sion or substantial upgrades will be required to transmit $40,000 \mathrm{GWh}$ of wind power every year (19). A recent study by NREL regarding increasing wind generation in the Eastern Interconnect comes to a similar conclusion (20). The need for an accurate estimate of new transmission requirements appears less urgent when considering that the costs of upgrading existing transmission lines are likely to be only $20 \%$ lower than the costs of constructing new transmission (19).

In what follows, we present estimates of the costs of new transmission capacity and use those estimates to explore the economics of local versus distant wind assuming different requirements for new transmission in the case study region. We examine four transmission scenarios for distant wind: 1) a pessimistic scenario where new transmission capacity is required from the wind site to the load; 2) a $50 \%$ scenario where new transmission is required for the equivalent of $50 \%$ of the distance between the wind site and the load; 3 ) a $25 \%$ scenario where $25 \%$ of this distance requires new transmission; and 4) a scenario where all distant wind development requires $100 \mathrm{~km}$ of new transmission to connect to the existing grid. For all four transmission scenarios we assume that any new HVDC transmission is built from the wind site to the load. HVDC transmission in the United States is primarily used to transmit large quantities of power over long distances or to enable power transfer between interconnections and is not well suited for short distances because of the cost of converters (21). We estimate transmission losses and capacity constraints based on the time series output of the different DCF categories assuming the distance the power must travel is equal to the straight line distance between the wind site and the load. Although transmission losses and transmission constraints for the $50 \%, 25 \%$, and $100 \mathrm{~km}$ transmission scenarios will depend on the available transmission capacity and power flows on the grid, we estimate these values using the assumptions from transmission scenario 1 (see Supporting Information section 9) due to a lack of data on existing grid capacity and future operation.

3.9. Capital Costs of New Transmission. Acquiring approval to site and build new extra high voltage transmission lines on new rights-of-way, especially lines crossing state or other jurisdictional boundaries, can take years or even decades in the United States (22). Because of this and other issues, estimates of the cost of new high voltage transmission lines presented in planning studies of RTOs/ISOs, state planning agencies, and federal reports vary widely, even within the same planning area (see Supporting Information section 10).

Table 3 presents capital cost estimates for long distance HVAC and HVDC transmission and the length of new transmission required in each state, by wind DCF resource and transmission scenario. Estimates for $230 \mathrm{kV}$ lines are based on cost averages from the Midwest ISO Transmission Expansion Plan 08 Appendix A projects (23). Cost estimates for $345 \mathrm{kV}, 500 \mathrm{kV}$, and $765 \mathrm{kV}$ AC lines in each state are assumed to be equal to the state level cost estimates from the Midwest ISO Regional Generator Outlet Study (RGOS) (2009) (19). We add a $25 \%$ cost contingency for all new HVAC transmission to account for substation costs as is done in RGOS. For HVDC transmission we assume bipolar $500 \mathrm{kV}$ lines and use cost estimates from LBNL's The Cost of Transmission for Wind Energy: A Review of Planning Studies (2009) (24). We assume that the cost of a 3000 MW HVDC converter is $\$ 250$ million.

\section{Results}

Levelized Capital Cost per kWh of Generation. Figure 3 shows estimates of the cost of electricity (COE) $(\$ / \mathrm{kWh})$ assuming a $10 \%$ discount rate, 20 years of economic life, and the low estimates for wind farm capital cost (see Supporting Information section 11 for lowest COE by installed capacity). For all distant wind DCF categories, costs decrease with increasing electricity volumes of up to $5000 \mathrm{GWh}$ due to economies of scale in transmission, but the cost benefits are nonlinear. At $6000 \mathrm{GWh}$ an HVDC line (assumed to be built from site to load for all scenarios) becomes the optimal transmission option for distant wind, causing a slight increase in the cost of COE, but also exhibits economies of scale by reducing the COE for $8000 \mathrm{GWh}$ and 10,000 GWh.

Under scenarios 1 and 2, the local wind resource has the lowest COE for all circumstances, although for high quantities of delivered electricity the cost difference between local and distant sites becomes very small.

Transmission scenarios 3 and 4 are more favorable to distant wind resources than scenarios 1 and 2, and local wind resource is no longer the lowest cost resource for all cases, although it has the lowest cost (or close) for a number of conditions. Under transmission scenario 3, the local wind resource has a COE that is less than $10 \%$ higher than the minimum COE for almost all cases except $5000 \mathrm{GWh}$ and $6000 \mathrm{GWh}$. Under transmission scenario 4 , the local wind resource has the lowest COE for the $8000 \mathrm{GWh}$ and 10,000 GWh cases. The $39.5 \%$ DCF resource and the $42 \%$ DCF resource have the lowest COE for the rest of the cases, but the difference with the other distant wind DCF categories is less than $10 \%$.

Assuming a high estimate of wind farm capital costs ( $\$ 2417 / \mathrm{kW}$ for local wind and $2120 / \mathrm{kW}$ for distant wind) favors the economics of the distant wind DCF categories. However, as shown in Supporting Information (section 12), the only noticeable difference from the results previously discussed is that local wind is no longer the lowest COE resource for $10,000 \mathrm{GWh}$. The $41 \%$ DCF category has the 
TABLE 3. New HVAC and HVDC Transmission Line Cost Estimates (\$M/km) and Length of New HVAC Transmission in Each State under the Four Transmission Scenarios

transmission costs (\$M/km)

$\begin{array}{ll}230 \mathrm{kv} & \text { NA } \\ 345 \mathrm{kv} & 1.24 \\ 500 \mathrm{kv} & 2.17 \\ 765 \mathrm{kv} & 2.98 \\ 500 \mathrm{kv} \text { HVDC } & 1.86\end{array}$

length of transmission required in each state under transmission scenarios $(\mathrm{km})$

Scenario $1(100 \% \text { of distance site to load })^{d}$

$36 \% \mathrm{CF}, 50 \mathrm{~km}$

$39.5 \% \mathrm{CF}, 550 \mathrm{~km}$

$41 \% \mathrm{CF}, 650 \mathrm{~km}$

$42 \% \mathrm{CF}, 750 \mathrm{~km}$

Scenario $2(50 \% \text { of distance site to load })^{d}$

$36 \% \mathrm{CF}, 50 \mathrm{~km}$

$39.5 \% \mathrm{CF}, 550 \mathrm{~km}$

$41 \% \mathrm{CF}, 650 \mathrm{~km}$

$42 \% \mathrm{CF}, 750 \mathrm{~km}$

Scenario 3 ( $25 \%$ of distance site to load) ${ }^{d}$

$36 \% \mathrm{CF}, 50 \mathrm{~km}$

$39.5 \% \mathrm{CF}, 550 \mathrm{~km}$

$41 \% \mathrm{CF}, 650 \mathrm{~km}$

$42 \% \mathrm{CF}, 750 \mathrm{~km}$

Scenario $4(100 \mathrm{~km})^{d}$

$36 \% \mathrm{CF}, 50 \mathrm{~km}$

$39.5 \% \mathrm{CF}, 550 \mathrm{~km}$

$41 \% \mathrm{CF}, 650 \mathrm{~km}$

$42 \% \mathrm{CF}, 750 \mathrm{~km}$
$I^{b}$

$\mathrm{NA}^{a}$

0.93

1.86

2.61

1.86

MN

$-$

142

- $\quad 458$

- 2 -

142

142

- $\quad 52.5$

$\begin{array}{ll}- & - \\ - & 100\end{array}$

100
275

183

240

-

137.5

20.5

$\mathrm{IL}^{\mathrm{b}}$

0.57

1.24

2.05

2.61

1.86

IA

400

338

58

$-$
$\mathrm{NB}^{c}$

$\mathrm{NA}^{a}$

0.62

1.62

2.61

1.86

${ }^{a}$ Not applicable; $230 \mathrm{kV}$ lines do not have the required capacity to transmit power from the distant wind sites. ${ }^{b}$ Costs of $500 \mathrm{kV}$ transmission in lowa (IA), Illinois (IL), and Nebraska (NB) are estimated based on the ratios of $345 \mathrm{kV}$ double circuit and $765 \mathrm{kV}$ costs in those states (see Supporting Information section 10) to costs in Minnesota (MN) and then multiplied by the cost of $500 \mathrm{kV}$ in MN. ${ }^{c}$ Nebraska (NB) cost estimates are assumed to be same as for the Dakotas. ${ }^{d}$ For all four transmission scenarios any new HVDC transmission is built from the wind site to the load.
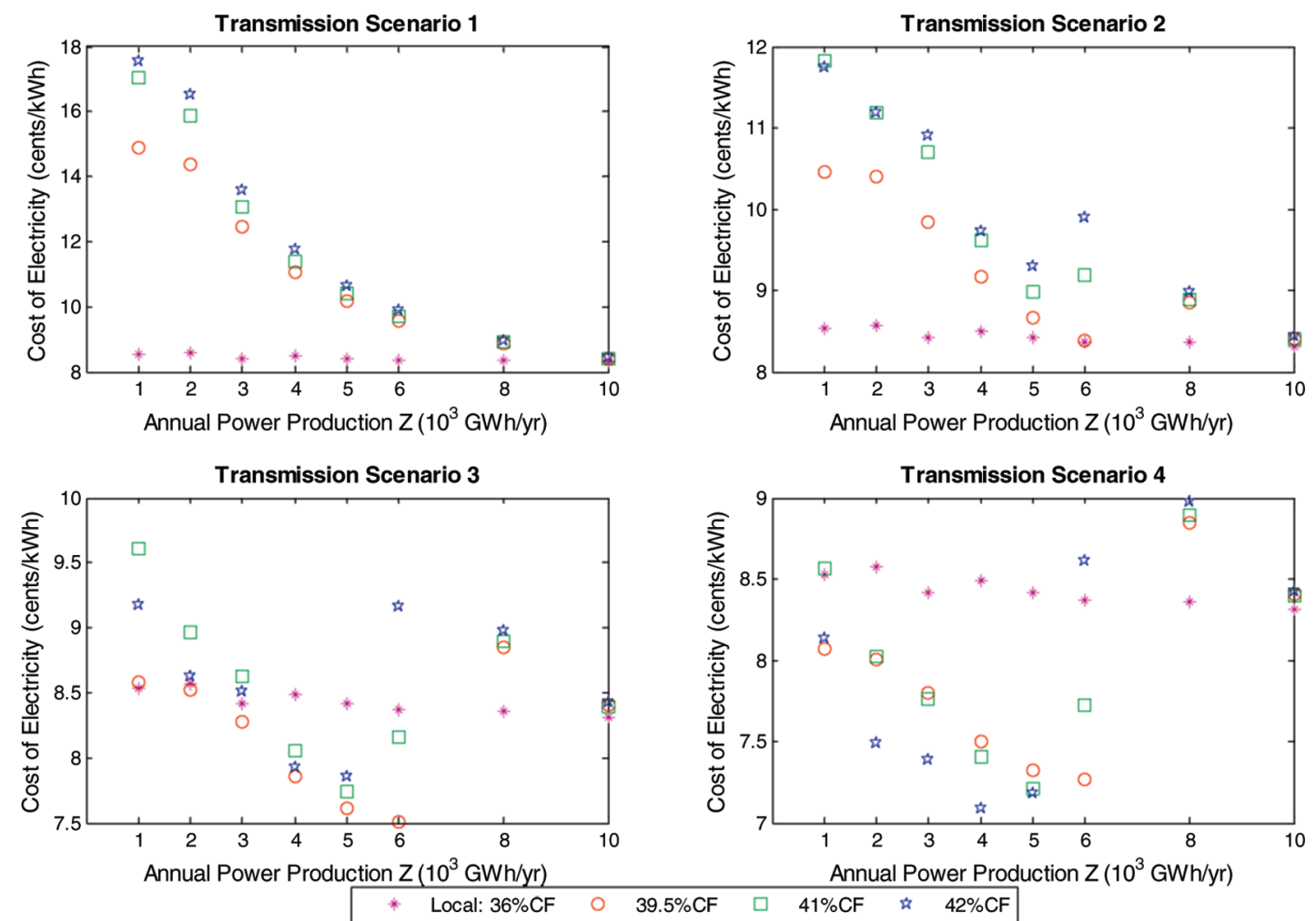

FIGURE 3. Cost of electricity (COE) of different wind DCF categories $(\$ / \mathrm{kWh})$. COE assumes $10 \%$ discount rate, 20 years of economic life, and a low estimate for capital costs of wind farm (\$2181/kW for local wind and $\$ 1913 / \mathrm{kW}$ for distant high CF wind). 
lowest COE in this case, but, as before, the difference with the other DCF categories is very small.

\section{Discussion}

We conclude that although the cost savings from reduced capital cost of wind farms in higher CF sites can be significant (139-190 \$M for $1000 \mathrm{GWh}$ and 1386-1901 \$M for 10,000 GWh) they might be insufficient to offset the costs of building or upgrading transmission lines as well as the costs of the thermal losses that are exacerbated when large quantities of power are transmitted over long distances. The analysis presented can help inform the first stages of the decision making process on capital investments to meet a state RPS with wind. However, an accurate comparison of the economics of local and distant wind requires a precise estimate of the cost to transmit power, which is a function of the power transmission capacity and losses of the existent grid, the needs and costs of new transmission and upgrades, and the transmission policy and corresponding cost allocation rules. Given the uncertainty that surrounds the costs of long distance power transmission, investors might assign a riskpremium to distant wind resources that will make local resources even more attractive.

Results from the case study illustrate how an increase in the distance of power transmission reduces transmission capacity and increases thermal losses, which results in additional required nameplate capacity of the distant wind farm, significantly augmenting its costs and reducing its advantages in relation to local wind development.

Our analysis of the Illinois RPS shows that the lowest cost (or nearly lowest) resource to supply up to $10,000 \mathrm{GWh}$ per year of wind energy $(\sim 3.1 \mathrm{GW})$ to a substation outside of Chicago is the local wind resource if the length of the new transmission lines required is between $100 \%$ and $50 \%$ the distance between the site and the load. When the length of the new transmission line required is $25 \%$ the distance between the wind farm and the load all the wind DCF categories have very similar economics, and the local wind resource has the lowest COE (or nearly lowest) for 6 of the 8 levels of electricity requirements analyzed. In the case where only $100 \mathrm{~km}$ of new transmission is required to integrate the distant wind resources, distant DCF categories can be more economical, but their advantage is not as strong as expected due to the need for higher installed capacities to guarantee the required level of delivered power in the presence of transmission constraints and losses.

Considering the difficulties, delays, and risks associated with the construction and upgrades of new long distance power transmission required for distant wind resources, it becomes clear that if wind investors are required to pay all or part of the capital cost of long distance transmission to access higher CF wind, they will likely opt for lower CF wind requiring smaller transmission investments. Distant wind development will require the implementation of innovative transmission cost allocation mechanisms that increase long distance power transfer capacity and reduce transmission costs for wind investors (as proposed by ref 25 for example).

The COE estimates of this study demonstrate that wind continues to be an expensive source of electric power if there is no price on $\mathrm{CO}_{2}$ emissions. Our estimates do not include wind operating costs such as the costs of redispatch of other generators in the system or the costs associated to reactive power control, and yet are between $31 \%$ and $74 \%$ higher than the COE of a new conventional coal plant $(\$ 0.071 / \mathrm{kWh}-$ $\$ 0.094 / \mathrm{kWh}$ compared to $\$ 0.054 / \mathrm{kWh}(26)$ ), and are at least $50 \%$ higher than average wholesale prices in the Midwest ISO in 2008 (27). However a carbon price of $\$ 18 /$ tonne to $\$ 43 /$ tonne would make wind power competitive with a new, uncontrolled coal plant (assuming the coal plant emits
0.93tonneCO2/MWh). When compared to an IGCC plant with a Selexol $\mathrm{CO}_{2}$ emissions control or a pulverized coal plant with amine-based $\mathrm{CO}_{2}$ emissions control $(\$ 0.087 / \mathrm{kWh}$ $\$ 0.128 / \mathrm{kWh}(26)$ ) wind power could have a lower or slightly lower COE.

\section{Acknowledgments}

We thank Willem Fadrhonc, Congnan Zhan, Anne Eshleman, Kyle Bradbury, and three anonymous reviewers whose comments greatly improved this manuscript. Funding for this work was provided by the Climate Change Policy Partnership at Duke University, and by the National Science Foundation under award \#SES-0345798.

\section{Supporting Information Available}

Additional text, tables, and figures. This material is available free of charge via the Internet at http://pubs.acs.org.

\section{Literature Cited}

(1) Wiser, R.; Bolinger, M. 2008 Wind Technologies Market Report; DOE/GO-102009-2868; U.S. Department of Energy, National Renewable Energy Laboratory: Golden, CO, 2009.

(2) U.S. Energy Information Administration. Assumptions to the Annual Energy Outlook 2009 Electricity Market Module. http:// www.eia.doe.gov/oiaf/aeo/assumption/electricity.html (accessed January 28, 2010).

(3) Database of State Incentives for Renewables \& Efficiency. Summary Maps. http://www.dsireusa.org/summarymaps/ index.cfm?ee $=1 \& R E=1$ (accessed October 16, 2009).

(4) U.S. Environmental Protection Agency. Renewable Portfolio Standards Fact Sheet. http://www.epa.gov/chp/state-policy/ renewable_fs.html (accessed October 19, 2009).

(5) Database of State Incentives for Renewables and Efficiency. Illinois Incentives/Policies for Renewables and Efficiency. http://www.dsireusa.org/incentives/incentive.cfm?Incentive_ Code $=$ IL04R\&re $=1 \&$ ee $=1$ (accessed October 16, 2009).

(6) DeCarolis, J. F.; Keith, D. W. The economics of large-scale wind in a carbon constrained world. Energy Policy 2006, 34 (4), 395410.

(7) Greenblatt, J. B.; Succar, S.; Denkenberger, D. C.; Williams, R. H.; Socolow, R. H. Baseload wind energy: modeling the competition between gas turbines and compressed air energy storage for supplemental generation. Energy Policy 2007, 35 (3), 1474-1492.

(8) Cavallo, A. Controllable and affordable utility-scale electricity from intermittent wind resources and compressed air energy storage (CAES). Energy 2007, 32 (2), 120-127.

(9) Pattanariyankool, S.; Lave, L. B. Optimizing Transmission from Distant Wind Farms; Carnegie Mellon Electricity Industry Center Working Paper; 2008.

(10) Denholm, P.; Sioshansi, R. The value of compressed air energy storage with wind in transmission-constrained electric power systems. Energy Policy 2009, 37 (8), 3149-3158.

(11) Geoffrey, L. High value wind: A method to explore the relationship between wind speed and electricity locational marginal price. Renewable Energy 2008, 33 (8), 1843-1853.

(12) Charles River Associates. SPP WITF Wind Integration Study; Southwest Power Pool; 2010.

(13) Brower, M. Development of Eastern Regional Wind Resource and Wind Plant Output Data Set; U.S. Department of Energy, National Renewable Energy Laboratory: Golden, CO, 2008.

(14) EnerNex Corporation. Eastern Wind Integration and Transmission Study: Executive Summary and Project Overview; U.S. Department of Energy, National Renewable Energy Laboratory: Golden, CO, 2010.

(15) National Renewable Energy Laboratory. Wind Integration Datasets. Obtaining the Eastern Wind Dataset. http://www. nrel.gov/wind/integrationdatasets/eastern/data.html (accessed September 8, 2009).

(16) Burton, T.; Sharpe, D.; Jenkins, N.; Bossanyi, E. Wind Energy Handbook; John Wiley \& Sons: West Sussex, 2001.

(17) Fingersh, L.; Hand, M.; Laxson, A. Wind Turbine Design Cost and Scaling Model; U.S. Department of Energy, National Renewable Energy Laboratory: Golden, CO, 2006.

(18) U.S. Department of Energy: Energy Efficiency and Renewable Energy. Electric Power and Renewable Energy in Illinois. http:// apps1.eere.energy.gov/states/electricity.cfm/state=IL\#total (accessed November 5, 2009). 
(19) Midwest ISO. Regional Generator Outlet Study Phase I Executive Study Report; Midwest ISO; 2009.

(20) EnerNex Corporation. Eastern Wind Integration and Transmission Study; U.S. Department of Energy, National Renewable Energy Laboratory: Golden, CO, 2010.

(21) Bahrman, M.; Johnson, B. The ABCs of HVDC transmission technologies: An overview of high voltage direct current systems and applications. IEEE Power Energy Mag. 2007, 5 (2), 32-44.

(22) Vajjhala, S. P.; Fischbeck, P. S. Quantifying siting difficulty: A case study of US transmission line siting. Energy Policy 2007, 35 (1), 650-671.

(23) Midwest ISO. The Midwest ISO Transmission Expansion Plan 2008; Midwest ISO; 2008.
(24) Mills, A.; Wiser, R.; Porter, K. The Cost of Transmission for Wind Energy: A Review of Transmission Planning Studies; Lawrence Berkeley National Laboratory: Berkeley, CA, 2009.

(25) Wright \& Talisman, P. C. SPP Highway Byway Cost Allocation Filing. Southwest Power Pool. http://www.spp.org/ publications/Highway Byway Filing.pdf (accessed June 8, 2010).

(26) Carnegie Mellon University Center for Energy and Environmental Studies. IECM-cs 6.2.4 (c), 2010 Integrated Control Model, Carbon Sequestration Edition. http://www.cmu.edu/ $\mathrm{epp} / \mathrm{iecm} /$ (accessed June 10, 2010).

(27) Potomac Economics. 2008 State of the Market Report for the Midwest ISO; Midwest ISO; 2009.

ES100751P 